\title{
Reflexões sobre a função social do professor na universidade
}

\author{
Lais Boveto \\ Terezinha Oliveira \\ Universidade Estadual de Maringá
}

Resumo

Neste artigo, abordamos questões consideradas cruciais para a formação docente, partindo de ideias e condutas naturalizadas na educação. $\bigcirc$ cotejo dos aspectos que fundamentam a função social do professor é estabelecido com base na história, especificamente na origem medieval da universidade. A finalidade principal é ressaltar a noção de que disciplina abrange o esforço e a responsabilidade, que são características essenciais para a formação, fazem parte do conjunto de conhecimentos que o professor necessita para sua atuação. Para tanto, seguiremos os princípios teórico-metodológicos da História Social, particularmente em relação ao conceito de fundamentum de Marc Bloch e de longa duração de Fernand Braudel. Desse modo, entendemos que um dos resultados da divisão (ou hierarquização) entre teoria e prática é a fragilidade do conhecimento, prejudicial à educação em todos os níveis, pois atuamos por meio do conhecimento que possuímos.

Palavras-chave: Universidade Medieval. Formação docente. Disciplina.

\section{Reflections on the social function of the university professor}

\section{Abstract}

In this article, we approached the issues considered crucial for teacher training, starting at the habitual ideas and behaviors in education. The comparison of aspects which support the teacher's social role is established based on History, specifically on the medieval origins of the university. The main purpose is to highlight the notion that discipline include effort and responsibility, that are essential features for training as well as make part of a knowledge that a teacher needs for his performance. We follow the principles theoretical and methodological of Social History, particularly the Marc Bloch's concept of fundamentum and the perspective of long-term developed by Fernand Braudel. We understand that one of results of division (or ranking) between theory and practice is the fragility of knowledge, harmful to education at all levels, once we act by using the knowledge we have.

Keywords: Medieval University. Teacher training. Discipline. 
Reflexões sobre a função social do professor na universidade

\section{Reflexiones sobre la función social del profesor universitario}

\section{Resumen}

En este artículo, analizamos cuestiones consideradas cruciales para la formación docente, a partir de las ideas y los comportamientos naturalizados en la educación. El debate acerca de los aspectos que apoyan la función social del maestro se establece en base a la historia, específicamente el origen de la universidad en la Edad Media. El objetivo principal es acentuar la idea de que la disciplina abarca el esfuerzo y la responsabilidad que son características esenciales para la formación, son una parte del conjunto de conocimientos que el maestro necesita para su trabajo. Para eso, seguimos los principios teóricos y metodológicos de la Historia Social, en particular el concepto de fundamentum de Marc Bloch y el largo tiempo de Fernand Braudel. Entendemos que uno de los resultados de la división (o jerarquía) entre la teoría y la práctica es la fragilidad del conocimiento, perjudicial para la educación en todos los niveles, a medida que actuamos a través del conocimiento que tenemos.

Palabras clave: Universidad Medieval. Formación del profesorado. Disciplina.

\section{Introdução}

Neste artigo, refletiremos sobre questões contemporâneas da educação, particularmente considerando a 'disciplina' ${ }^{1}$ na formação e na ação docente que são eixos centrais nos processos educativos. Entendemos ambos (formação e ação) como indissociáveis e interdependentes, por este motivo, principiamos a nossa análise narrando um episódio que ocorreu há poucos anos, em uma aula da pós-graduação em Educação. $\bigcirc$ discurso de um dos professores e as leituras realizadas no decorrer do curso originaram essa reflexão.

Diante das angústias dos alunos em relação à produção da dissertação exigida para a conclusão do curso, o professor (docente há mais de 20 anos no ensino superior) alertou para o que ele considerava ansiedade exagerada e autocobrança excessiva. Manifestou o incômodo que sentia ao ver que havia alguns colegas seus que 'aterrorizavam' os alunos exigindo que fizessem leituras e trabalhos muito complexos; comentou, inclusive, que soube que havia docentes que obrigavam seus filhos, ainda muito jovens, a realizar leituras de textos clássicos, o que ele considerava um grande absurdo. Encerrou suas 
reflexões afirmando que os alunos deviam relaxar, pois a vida não poderia se resumir aos estudos. Muitos alunos sorriram, alguns com certo alívio.

Retomamos, portanto, essa breve narrativa por considerarmos o docente - tanto em relação a sua formação, quanto atuação - como o alicerce que sustenta o ensino e, por conseguinte, a aprendizagem. A ação do professor marca e influi na vida dos alunos e, nesse sentido, as ideias presentes nesse discurso que, a princípio, pode parecer inocente - somente um comentário sem intenção alguma -, revelam noções que permeiam, em geral, a Educação no país. Entre elas, destacamos a necessidade de tornar o ensino mais suave e ameno, subestimando a capacidade de os alunos se dedicarem a temas mais complexos e desencorajando o empenho e a responsabilidade. Por um lado, há professores que se queixam dos alunos que não têm disciplina, por outro, ao que parece, há aqueles que minimizam a importância desse aspecto na própria formação docente. Dessa maneira, desde o início da vida escolar, os jovens são submetidos a uma forma de ensino que exige muito pouco de sua responsabilidade e dedicação e, ao mesmo tempo, são constantemente cobrados por sua falta de disciplina para o estudo e a para a vida. Salientamos que não consideramos disciplina como submissão, sujeição ou ausência de liberdade, pelo contrário, o termo disciplina será tomado por dois significados que se complementam, indicando tanto o respeito às regras, quanto a determinação e disposição para realizar algo, ou seja, une qualidades como responsabilidade, dedicação e comprometimento². Dessa maneira, recorremos aos pensadores que têm sido objeto de nossas pesquisas na perspectiva de longa duração da história e a informações e fatos recentes relativos à educação em nosso país para formularmos um entendimento sobre essas questões.

Tomamos como referência a ideia de conhecimento e de instituição/ instituição educativa encontrada nos princípios que marcaram as origens da Universidade na ldade Média. $\bigcirc$ ponto de partida dos mestres medievais era pensar o conhecimento como indissociável da ação dos indivíduos que dela fazem parte. Desse modo, analisaremos o papel da universidade especialmente no que concerne à formação integral, fundamentada no conhecimento, e como esta interfere, por meio das licenciaturas, em outros níveis do ensino, demonstrando a indissociabilidade da formação e da atuação docentes, por conseguinte, do que concebemos como teoria e prática educativa.

Propomos, portanto, pensar sobre a responsabilidade - como conceito explícito na noção de disciplina - dos professores universitários, especialmente 
nas licenciaturas, em relação à qualidade no ensino básico. Nossas reflexões partem de uma concepção social de educação na qual há uma relação de circularidade entre a formação do docente e a sua prática. Logo, é possivel questionar: qual a responsabilidade do professor da pós-graduação, cujo discurso apresentamos, para melhoria ou agravamento desse problema? Por se tratar de uma aula de um programa na área da educação, que atende a todas as licenciaturas, principalmente, o curso de Pedagogia, esse pensamento pode fazer parte da formação de profissionais que atuarão em todos os níveis de ensino ${ }^{3}$. Podemos perceber que, ao reforçar a necessidade de que os professores em formação não se preocupem demasiadamente com os estudos, duas mensagens são evidenciadas: a primeira, conforme já apontamos, é minimizar as preocupações em relação ao estudo, desvinculando-as da disciplina, particularmente em seu sentido de esforço e responsabilidade. A segunda é tratar a leitura e o estudo, especialmente dos clássicos, como algo desagradável por ser complexo e que, portanto, deve ser suavizado ou descartado, especialmente para os mais jovens. Naturalizam-se ${ }^{4}$, desse modo, essas percepções que serão disseminadas pelos professores em formação como algo também natural. Os professores, ao terem essa noção do conhecimento, no momento 214 de sua formação, tendem a amenizar as atividades que exigem grande esforço por parte dos alunos e, por outro lado, os alunos apresentam cada vez mais motivos para não realizar esforços no momento da aprendizagem.

Assim, aliada a essa necessidade de 'facilitar' a obtenção de diplomas (nas escolas e universidades), independentemente da leitura e da aquisição do conhecimento, é necessário tratar da eterna dicotomia atribuída à relação entre a teoria e a prática na educação. É muito expressivo, por exemplo, o número de professores que se questionam sobre qual seria o conteúdo mais relevante para ser aprendido e ensinado 5 . Nas escolas, especialmente, os professores que já passaram pelo ensino superior, muitas vezes, não conseguem estabelecer a relação entre o que foi estudado na licenciatura e o cenário com o qual se deparam nas salas de aula. Aparentemente, também não há um interesse efetivo, por parte dos organizadores dos currículos das licenciaturas, para que essa relação seja estabelecida ou mesmo compreendidab.

A Base Nacional Comum Curricular, documento em elaboração que deveria ser destinado a sintetizar os conteúdos obrigatórios das matérias escolares, é um reflexo recente dessas imprecisões na formação docente. Inúmeras 
são as incoerências conceituais. Como exemplo, podemos citar a disciplina de História.

O componente curricular História tem por objetivo viabilizar a compreensão e a problematização dos valores, dos saberes e dos fazeres de pessoas, em variadas espacialidades e temporalidades, em dimensões individual e coletiva.

$[\ldots]$

Uma questão central para o componente curricular História são os usos das representações sobre o passado, em sua interseção com a interpretação do presente e a construção de expectativas para o futuro. As análises históricas possibilitam, assim, identificar e problematizar as figurações construídas por e sobre sujeitos em suas diferentes noções de tempo, de sensibilidade, de ritmos (BASE NACIONAL COMUM CURRICULAR, 2015, p. 2411.

Mais adiante, os elaboradores do componente de História prosseguem com indicações do modo como os conteúdos serão tratados no ensino fundamental:

Para tanto, enfatiza-se a História do Brasil como o alicerce a partir do qual tais conhecimentos serão construídos ao longo da Educação Básica. Tal ênfase, é importante ressaltar, não significa exclusividade na abordagem da história brasileira nem tampouco a exclusão dos nexos e articulações com as histórias africanas, americanas, asiáticas e europeias [...].

A percepção da historicidade presente em questões do cotidiano favorece a compreensão do passado de pessoas, individual e coletivamente, em suas dimensões política, econômica, cultural e social $[\ldots]$.

Aos anos finais do Ensino Fundamental cabe o desenvolvimento de conhecimentos necessários ao enfrentamento de processos históricos, enfatizando-se o estudo da História do Brasil e de indivíduos e coletividades que demarcaram mudanças e permanências nas conformações sociais, econômicas, culturais e políticas da trajetória histórica brasileira, o que envolve, como sinalizado anteriormente, o estabelecimento de nexos com processos ocorridos em outras partes do mundo, marcadamente nas Áfricas, nas Américas e nos mundos europeus (BASE NACIONAL COMUM CURRICULAR, 2015, p. 242, grifo nosso). 
Salientamos que apresentamos essas passagens com a finalidade de oferecer uma noção da proposta estabelecida, pois, no documento, há indicações ano a ano, contemplando todo o ensino fundamental e médio. Inicialmente, afirma-se a proposta de que o aluno entenda as relações humanas em diferentes espaços e tempos e, posteriormente, indica como conteúdos a serem ensinados prioritariamente aqueles que se referem à história brasileira. Por haver recebido inúmeras críticas, inclusive do próprio ministro da educação là época, o professor Renato Janine Ribeiro conduziu a elaboração do documento), os elaboradores acrescentaram explicações sobre o foco quase exclusivo no Brasil. Algumas questões elementares podem ser suscitadas com a leitura dessas passagens: como oferecer noção de temporalidade e espacialidade adequadamente promovendo a ideia de que é possível entender a história da humanidade a partir da história de um país relativamente jovem como o Brasil? Ao propor que se ensine a disciplina partindo da história nacional, priorizando as inter-relações e os nexos com outros países, devemos supor que apresentaremos aos alunos uma historiografia iniciada no século XVI? Observemos, primeiramente, que o documento prevê conteúdos para o ensino que principiará com crianças de 6 anos e se encerrará com adolescentes de

21617 anos. Sob este aspecto é preciso considerar as diferenças que ocorrem nos processos mentais de formação na infância e adolescência, em relação a conceitos como, por exemplo, tempo e espaço. A Base, que tinha por finalidade orientar e tornar mais objetiva a seleção de conteúdos a serem ensinados, estabelece, do nosso ponto de vista, ainda mais confusões, pois, além de não deixar claro como esses conteúdos serão trabalhados, busca aplicar uma concepção de história em que um país se torna o centro das questões a serem compreendidas - como se a história existisse relativamente ou em função de um acontecimento, como o descobrimento do Brasil.

Vemos, assim, que a Base Nacional Comum Curricular é um dos documentos que podem ser analisados e que indicam a relação de mutualidade entre o ensino superior e o ensino básico. A maneira de lidar com o conhecimento teórico - que pode ser compreendida, também, pela análise dos currículos das licenciaturas - é disseminada pelas universidades e interfere diretamente na educação recebida pelos jovens nas escolas. No caso da teoria relativa à disciplina de história, transmite-se, vinculado aos conteúdos propostos, um modo de olhar para o conhecimento e, por consequência, um 
modo de compreender o presente. Logo, não se trata de uma proposta neutra, mas está carregada de subjetivações políticas7.

Segundo Marc Bloch (2001, p. 68), a história trata da vida, dos aspectos humanos que sobrevivem desde os tempos mais longínquos e que nos permitem compreender o presente e atuar nele. Assim, o estudo de um tempo específico e limitado leva a um entendimento parcial do próprio período estudado. Com isso, o autor não questiona a existência dos especialistas em um ou outro tema, somente alerta para o fato "[...] de que as investigações históricas não sofrem de autarquia. Isolado, nenhum deles jamais compreenderá nada senão pela metade [...]; e a única história verdadeira, que só pode ser feita através de ajuda mútua, é a história universal". Ao estudar um tempo ou tema específico é necessário, ao menos, ter em mente como estes se situam em relação à história geral. Nesse sentido, podemos observar que a aquisição da noção de temporalidade histórica depende do estudo do passado remoto, tanto quanto da percepção de que as divisões na história só ocorrem em nome de um aprimoramento da compreensão da história universal.

Portanto, buscar na teoria histórica elementos que se ajustem à atualidade, ou que atendam às nossas necessidades cotidianas - ou mesmo nacionais - implica uma distorção do que seja a ciência histórica. No caso da concepção presente na BNCC, reforça-se essa atitude ao indicar um ensino que tem por base e fundamento o nosso próprio país e o nosso cotidiano. Nesse sentido, será uma disciplina predominantemente inútil, afinal, na maior parte do tempo, não se adequará a essas finalidades. Ocorre, dessa maneira, uma forma de estímulo ao desgaste da teoria em geral, ou de torná-la o que Bloch (2001, p. 62) denomina de "[...] inofensivo luxo do espírito".

Derivada dessa expectativa em relação ao conhecimento teórico, uma situação comum é a de professores que 'acusam' os pesquisadores da educação (muitos deles, também professores) de não conhecerem a realidade da sala de aula (nas escolas) e, por esse motivo, proferirem discursos que desconsideram as dificuldades enfrentadas. A nosso ver, por meio das considerações sobre a história, podemos refletir que, primeiramente, as teorias têm sido 'ensinadas' com base tanto nessa falsa expectativa, quanto na ideia de que não é preciso esforço para lê-las e conhecê-las, portanto, elas, de fato, não têm sido ensinadas e, por conseguinte, apreendidas. Desse modo, não há como pensar e atuar por meio dessas teorias, assim como não há meio de avaliar se realmente é o 'excesso' de teoria que atrapalha a formação docente 
e/ou discente. Vincula-se a essa situação paradoxal, o imobilismo que parece atingir os docentes em todos os níveis, a resistência em detectar e enfrentar os problemas e em modificar e questionar posicionamentos teóricos e políticos que se baseiam em ideias 'mortas'8.

Certamente, é um debate delicado que abrange aspectos diversos e, também, formas de apreensão e inter-relação diferentes, mas é absolutamente urgente e necessário que seja realizado. A ação dos professores não está desvinculada de sua formação e da sua maneira de lidar com o conhecimento.

Também é quase completo o consenso em relação à precariedade dos cursos de magistério, pedagogia e licenciatura [...].

Mas a formação do educador tem sido apenas habilitação técnica, aquisição e domínio de informações e habilidades didáticas. Essa atividade deveria ser uma autêntica Bildung [termo alemão que designa formação humana em seu mais alto nível], formação humana em sua integralidade. Daí a complexidade dessa função social, que implica muito mais em condições pessoais, do que outras profissões nas quais a atividade técnica tem certa autonomia em relação à qualificação. Espera-se que qualquer profissional tenha todas as qualidades exigidas pelo convívio social, em nome do respeito à dignidade das outras pessoas [...]. Mas para que a atividade do educador seja fecunda, sua personalidade e condição pessoal exige esse perfil, senão os objetivos de sua intervenção técnica não se efetivam (SEVERINO, 2012, p. 142-143).

Conforme o autor, nenhuma outra profissão exige tanto em termos de formação como a do professor. Isso porque não demanda somente capacidade técnica e certa polidez para lidar com outras pessoas. A formação integral a qual Severino se refere abarca tanto a erudição, quanto o comportamento e, até mesmo, o afeto que tem para com seu ofício. Como já afirmava Tomás de Aquino (1224/25-1274): "[...] o ensino pressupõe um perfeito ato de conhecimento no professor [...]" (TOMÁS DE AQUINO, 2001, p. 41). Trata-se, portanto, de um perfeito conhecimento tanto da matéria a ser ensinada, quanto do comportamento que se espera do aluno.

Como professores universitários, especialmente atuando na formação de outros professores, nosso principal papel é refletir sobre nossa função dentro das instituições educacionais na sociedade. Com base nessa ideia, qual seria o objetivo fundamental do ensino que oferecemos? $\bigcirc$ que se deve constituir 
em centro da nossa dedicação e das nossas atenções? Só podemos nos aproximar de argumentos para desenvolver as respostas ao compreender algumas das ideias que permearam a origem do nosso ofício no interior das instituições universitárias. Essa é uma atividade que não deve ser finalizada, é um trabalho constante e indispensável, na medida em que a pessoa sempre está em formação, especialmente professor.

Para a reflexão proposta, inicialmente, trataremos de aspectos da universidade brasileira, que nos motivam a pensar sobre a finalidade dessa instituição na sociedade. Em seguida, teceremos considerações sobre a origem da corporação universitas e a sua característica de reunir pessoas cujo objetivo era o conhecimento. Com essa compreensão sobre a instituição, refletiremos sobre a relevância da dedicação e da disciplina como hábitos essenciais à formação do docente e, por conseguinte, à produção do conhecimento.

\section{Alguns aspectos sobre a universidade brasileira}

A instituição educativa nos ultrapassa em tempo e espaço, a geração atual não criou a universidade ou a escola, tampouco, conhece todas as formas possíveis para sua constituição. Não possuímos, na maior parte do tempo, a dimensão de nossa atuação dentro desses estabelecimentos, pois nos mantemos mais envolvidos na resolução das questões cotidianas. Dessa maneira, tendemos a pensar pouco sobre como esses espaços se tornaram necessários no decorrer da história. Com isso, privamo-nos de percepções que levem a observar a instituição como algo maior do que os indivíduos que dela fazem parte em cada tempo. Reconhecer isso é um dos primeiros passos para compreender melhor a complexidade que nos envolve nesses espaços de produção do conhecimento.

As instituições universitárias brasileiras - apesar de suas especificidades - podem ser analisadas por meio de um aspecto comum: o baixo desempenho nas avaliações internacionais. Nenhuma universidade brasileira figura entre as 100 melhores do mundo e, em 2013, no ranking da Times Higher Education (THE), as duas universidades que ocupavam as melhores posições entre as instituições brasileiras perderam suas colocações (Universidade de São Paulo (USP) - de $158^{\circ}$ para $226^{\circ}$ e Universidade Estadual de Campinas (UNICAMP) - de $251^{\circ}$ para $301^{\circ} 1^{9}$. Buscar as causas desse baixo desempenho não é tarefa simples. Aliás, a simplificação tem sido, provavelmente, parte 
do problema. Utilizaremos como exemplo a USP, considerada a melhor instituição de ensino superior brasileira. Em relação ao ranking acima, o vice-reitor proferiu as seguintes observações:

'A USP respeita tais classificações, mas não molda suas atividades a elas, mas sim às necessidades sociais', afirma Agopyan.

'Nossa pesquisa é reconhecida internacionalmente, o que pode ser expresso, por exemplo, na colocação alcançada na mais recente edição do ranking da Scimago [divulgado em setembro], em que a USP está entre as dez instituições mundiais que mais produzem trabalhos científicos de qualidade e relevância' (Gl GLOBO, 2014).

É importante observarmos que, segundo o vice-reitor, ao mesmo tempo que um ranking não molda as atividades da universidade, em outro serve de argumentação para exaltar essas mesmas atividades. Se o ranking em que a instituição vai mal não serve como guia para orientar as ações, aquele em que vai bem não deveria ser relevante como forma de demonstrar um bom desempenho. A incoerência da argumentação revela, entre outros aspectos, uma necessidade de justificativas, sem que estas estejam respaldadas pelo 220 reconhecimento das falhas, ou da designação de medidas que aprimorem o desempenho da universidade.

Em relação aos trabalhos científicos, mencionados pelo representante da USP, é importante pensarmos sobre o artigo, publicado em 2014 por uma revista de circulação nacional, intitulado: Uma praga da ciência brasileira: os artigos de segunda (ALLEGRETTI, 2014). Nele, é possivel visualizar alguns dados preocupantes, como o fato de que a Coordenação de Aperfeiçoamento de Pessoal de Nível Superior (CAPES) tem não só oferecido um bom conceito a veículos que desprezam o rigor científico, como também permite que os seus pesquisadores, até mesmo o ocupante do cargo de presidente da instituição, publiquem nesses periódicos sem credibilidade.

A fim de testar a idoneidade de editoras do modelo open Access com perfil duvidoso, o biólogo e jornalista John Bohannon enviou um manuscrito científico falso a 304 periódicos sediados em dezenas de países. Um deles foi a publicação brasileira Genetics and Molecular Research (GMR), de propriedade do biólogo Francisco Alberto de Moura Duarte, professor titular aposentado da Universidade de São Paulo e presidente da Fundação de Pesquisas Científicas de Ribeirão Preto. Além de o trabalho conter 
erros crassos, os biólogos que o assinavam (Roboodee Agnor, Annyassee Barree e Bellakah Motodayl foram simplesmente inventados, assim como o Instituto de Medicina Wassee, do qual diziam fazer parte, supostamente sediado na Eritreia. Das 304 editoras, 157 caíram na armadilha do americano e publicaram o artigo falso. A GMR, que tem jornais classificados com as notas A 1 e A2 no Qualis, estava entre elas. 'O jornalista agiu de má-fé', defende-se Duarte (ALLEGRETTI, 2014, p. 104-110).

Ao editor, professor aposentado da USP, coube a afirmação de que o jornalista agiu de má-fé, todavia, não houve menção à incorreção cometida pela equipe editorial, ou mesmo a demonstração de intenção de se apurar a situação, ou de assumir a responsabilidade pelo ocorrido. No artigo, há um destaque para as consequências das notas estabelecidas pela Capes, que são utilizadas para conceder financiamentos aos pesquisadores. Assim, ao desprezar o rigor científico para avaliar criteriosamente uma publicação, poderá haver "[...] pesquisadores beneficiados a partir de falsos méritos. E isso, muitas vezes, com recursos públicos" (ALLEGRETTI, 2014, p. 104-110).

De fato, o ranking da Times Higher Education utiliza os indicadores qualitativos de publicação científica, o que leva as universidades brasileiras a posições mais desfavoráveis do que quando somente os aspectos quantitativos são levados em conta. Segundo Phil Baty, responsável pelo ranking THE, o Brasil deveria preocupar-se com "[...] estudos de alto impacto que ampliem os limites de nossa compreensão do mundo" (ALLEGRETTI, 2014, p. 1 10).

É importante ressaltar que a intenção não é de fazer julgamento à Capes, ou à própria USP, para aferir se são boas ou más instituições, mas de apresentar o posicionamento de seus líderes diante dos problemas. Entendemos que toda e qualquer instituição tem e sempre terá problemas. Por esse motivo, se as pessoas assumem suas responsabilidades e demonstram, por meio de suas ações e palavras, que estão atentas para buscar resoluções, o resultado é o fortalecimento institucional. No caso de quem ocupa cargos de liderança isso é ainda mais significativo, a valorização da instituição e dos serviços que ela presta à sociedade parte de seus membros. Em relação à universidade, os professores ocupam, praticamente, todos os cargos de liderança, além de exercerem papel de líderes dentro das salas de aula, portanto, sua conduta expressa a relevância de todo o trabalho universitário. Exatamente por 
entendermos a função docente dessa maneira, as observações do professor na aula da pós-graduação despertaram as reflexões presentes neste texto.

Para encerrar nosso exemplo, o artigo do sociólogo José de Souza Martins ${ }^{10}$, A USP sob ataque, relata a crise vivida pela instituição no decorrer da greve em 2014. Aborda, justamente, a responsabilidade de alunos, professores e funcionários em relação ao que a universidade representa e destaca uma "[... ] cultura de depreciação do ensino e do estudo que consolida o desapreço pela missão essencial da Universidade" (MARTINS, 2014, p. 1). Para o sociólogo, os ataques sofridos por professores que não aderiram à greve - que não são negligentes com as atividades de pesquisa e ensino e são exigentes em relação ao desempenho dos alunos - demonstram que há uma inversão de valores. Mascaram-se os problemas reais que seriam merecedores de atenção e críticas e permite-se que uma parcela da comunidade acadêmica reivindique direitos que não são compatíveis com as atividades relativas ao ensino superior - alunos, por exemplo, se veem no direito de utilizar o nome e as dependências da instituição para festas que, nos últimos anos, têm resultado em mortes e violência sexual e moral' ${ }^{1}$.

Na USP, já não são as maiorias que decidem [...].

Há dias, uma professora foi agredida aos berros por um aluno num dos prédios do campus: 'Sou eu quem paga teu salário! Vou arruinar tua carreira!'. No retorno às aulas, após a greve, ela comunicara o calendário de reposição de aulas decidido pela direção de seu departamento, o que incluía aulas aos sábados e em horários diferentes do convencional [...].

Professores escolhidos a dedo estão sendo satanizados, transformados em objeto de manifestos e denúncias pelo simples fato de serem competentes na pesquisa e no ensino e exigentes no aprendizado de seus alunos [...].

Isso vale também para a minoria dos funcionários mais leais ao sindicato do que à Universidade, cuja precedência inverteram, como se fossem a finalidade da instituição e não os agentes das importantes atividades meios que completam a missão dos professores. [...] Vale ainda para a minúscula porção de professores que gosta do poder, mas não gosta da coragem de decidir com propriedade, de defender a instituição e a missão, os que tratam os alunos como imberbes pupilos de jardim da infância (MARTINS, 2014. s/p.). 
Martins faz alusão a várias questões, das quais destacamos o elemento comum: os partícipes da instituição não compreendem, e não parecem almejar compreender, suas funções dentro da universidade. $\bigcirc$ exercício de direitos é colocado acima dos deveres de cada um e aqueles que buscam se dedicar às atividades relativas ao conhecimento são hostilizados. Não se trata, portanto, de uma inversão de papeis ou de valores, mas sim, de uma deturpação sobre a função da instituição. Seja por ignorância, ou por oportunismo, a comunidade acadêmica se mantém à mercê do que Martins chama de 'minorias'. Evidenciamos, assim, várias faces de um mesmo problema: professores e pesquisadores isentam-se de suas responsabilidades com o ensino superior e se destituem da necessária autoridade para as atividades de pesquisa e ensino, o que fomenta um comportamento também incompatível por parte dos acadêmicos. Temos um quadro que abala todo o sistema educacional do país, tendo em vista que é, na universidade, que os professores e gestores se formam. Todavia, é essencial que se considere que esse quadro afeta o conjunto da sociedade, pois resulta, principalmente, de um comportamento naturalizado por grande parte das pessoas.

Outro dado importante, diretamente vinculado ao desempenho e à formação discente, é que, em meio a essa situação, os estudantes leem pouco ou nada em sua passagem pelo ensino superior. Segundo dados divulgados pela Andifes (Associação Nacional dos Dirigentes das Instituições Federais de Ensino Superior), os alunos no ensino superior leem apenas de um a quatro livros por ano. Na Universidade Federal do Maranhão, por exemplo, aproximadamente $23 \%$ dos estudantes não leem um livro sequer durante um ano e 28,5\% não frequentam a biblioteca (MOURA, 2011 1). O Fecomércio-RJ (Federação do Comércio do Rio de Janeiro), em pesquisa feita em 70 cidades brasileiras, revelou que $70 \%$ dos brasileiros não leram nenhum livro em 2014 (TELES, 2015). Já na pesquisa Retratos da Leitura no Brasil, publicada em 2012 , foram entrevistadas cinco mil pessoas, das quais aproximadamente $50 \%$ não são leitoras. Os resultados apontam que o brasileiro lê em média quatro livros por ano, mas, completa a leitura de aproximadamente dois enquanto na Espanha, por exemplo, cada pessoa lê em média dez livros por ano (ALENCASTRO, 2012). Um dado nessa pesquisa chamou a atenção da socióloga Zoara Failla (gerente do Instituto Pró-Livro até 2015): entre essas pessoas, somente 145 eram professores, dos quais apenas três disseram que gostavam de ler em seu tempo livre. A leitura preferida desses três professores 
eram livros de autoajuda e religiosos (POLATO, 2012). Segundo a estudiosa, isso é preocupante, tendo em vista que a formação de leitores passa, essencialmente, pelas escolas. Já no artigo Um terço dos professores não lê livros são apresentados os dados do questionário da Prova Brasil de 2011 , nos quais podemos observar um elevado percentual de professores que não têm interesse na leitura.

[... $21 \%$ dizem que leem às vezes e 34\% nunca entram em contato com um livro. [...] As causas são várias, entre elas a formação deficiente do docente, que não inclui a leitura como parte importante de seu desempenho profissional; a falta de tempo devido à dupla jornada para compensar os baixos salários; e o pouco incentivo do poder público.

No primeiro caso, a falta de valorização da leitura é apenas mais um fator da defasagem de qualidade dos cursos de Pedagogia e licenciatura, apontada pelos especialistas como um dos grandes problemas da educação hoje. Além de um currículo fraco, a carreira não consegue atrair jovens com um bom histórico escolar (SIMAS, 2013, s/p. grifo nosso).

224 Para nossa reflexão, destacamos a passagem em que se afirma que a formação docente não inclui a leitura como parte importante da formação, pois, de início, isso contraria a afirmação de que o problema das licenciaturas é o excesso de teoria. $\bigcirc$ que se pode depreender desses números é que tanto professores quanto alunos, em grande maioria, não demonstram interesse em relação à leitura. Evidentemente, também para esse fato há muitas justificativas, desde o custo dos livros, até a falta de tempo. No entanto, o que precisa ser considerado é o significado da leitura quando tratamos do processo de ensino e aprendizagem em qualquer instância. É possível oferecer uma boa formação nas licenciaturas e, por conseguinte, no ensino fundamental, prescindindo ou negligenciando a leitura? Quais os tipos e gêneros textuais são fundamentais para o desenvolvimento cognitivo? São questões que objetivamente norteariam a escolha dos conteúdos tanto para a formação dos professores, quanto para o ensino fundamental. Entretanto, raramente fazem parte da apreciação dos professores, pesquisadores e gestores, especialmente quando precisam responder pelo baixo desempenho avaliativo de aprendizagem das universidades e das escolas. 


\section{Laços entre as origens da Universidade e os nossos dilemas formativos}

Com o objetivo de compreender o papel que a universidade cumpriu em sua origem de modo que isso nos forneça, também, uma noção de nossas responsabilidades no presente, recorremos a autores que tratam da educação historicamente e, mais especificamente, que analisam o ensino superior a partir de seu início na ldade Média. A história, em nosso entendimento, desempenha um papel fundamental na prática educativa muitas vezes não reconhecido pelos professores e, por conseguinte, pelos alunos. A noção que se estabelece é de que conhecer a história não é necessariamente útil para, por exemplo, educar crianças no ensino fundamental, portanto, não seria uma disciplina relevante nas licenciaturas ${ }^{12}$. Trata-se, assim, da reflexão sobre teoria e prática apontada no início do texto, a qual, muitas vezes, segue uma única via na busca pela utilidade para o que pode ser conhecido pelo homem, em detrimento do conhecimento necessário (teórico) que é aquele que, justamente, diferencia o nosso intelecto na natureza. Essa diferença biológica é que determina, em última instância, a existência de instituições como a universidade, uma vez que se tudo o que é necessário ao homem fosse do universo da prática, provavelmente, não teríamos desenvolvido uma sociedade tão complexa.

homem somente se realiza plenamente como ser humano pela cultura e na cultura. Não há cultura sem cérebro humano laparetho biológico dotado de competência para agir, perceber, saber, aprender), mas não há mente (mind), isto é, capacidade de consciência e pensamento, sem cultura. A mente humana é uma criação que emerge e se afirma na relação cérebro-cultura (MORIN, 2000, p. 52).

Desse modo, conforme Morin, o cérebro humano é dotado de capacidade para desenvolver cultura e somente com ela se realiza plenamente. Não podemos, assim, desconsiderar que a principal atividade humana, da qual todas as outras dependem, é o pensar.

A Universidade conserva, memoriza, integra, ritualiza uma herança cultural de saberes, idéias, valores [...].

A esse título, a Universidade tem uma missão e uma função transeculares, que vão do passado ao futuro, passando pelo presente; 
conservou uma missão transnacional, apesar da tendência ao fechamento nacionalista das nações modernas. Dispõe de uma autonomia que the permite executar essa missão.

Segundo os dois sentidos do termo 'conservação', o caráter conservador da Universidade pode ser vital ou estéril. A conservação é vital quando significa salvaguarda e preservação, pois só se pode preparar um futuro salvando um passado, e estamos em um século onde múltiplas e poderosas forças de desintegração cultural estão em atividade. Mas a conservação é estéril quando é dogmática, cristalizada, rígida (MORIN, 2015, p. 81, grifo nosso).

Nessa passagem, Edgar Morin evidencia o que é o cerne da universidade e o submete à 'herança cultural de saberes' dos homens. A missão dessa instituição está vinculada diretamente à conservação dos conhecimentos produzidos pelos homens como seres biológicos e culturais. Essa percepção se aproxima muito das raízes medievais da universidade, tendo em vista que ela surge com o anseio dos homens por constituir um espaço onde pudessem se dedicar ao estudo.

Nesse sentido, para compreender historicamente a universidade, 226 julgamos necessário considerá-la a partir de algumas das características da sociedade medieval, especialmente, do século XIII. A instituição se apresenta como resultado do desenvolvimento citadino, da disputa de poder político entre realeza e papado e, também, da disseminação das ideias aristotélicas no Ocidente. Ao apresentar a origem da universidade medieval, Oliveira (2006) faz uma síntese da concepção do historiador Jacques Verger.

Segundo ele, diferentemente de Savigny e de Stenberghen, que procuram as origens dessa Instituição em um aspecto, uma lei, um grande acontecimento, Verger busca explicitar o nascimento da Universidade em função de elementos variados.

[...] do ponto de vista de Verger, não se pode entender as origens das Universidades sem considerar os acontecimentos sociais que marcaram o Ocidente medieval do século XIII. Exatamente por isso vincula sua origem aos principais aspectos históricos desse período (OLIVEIRA, 2006, p. 73).

Segundo a autora, Verger considera conflitos e avanços que levaram a três formas diferentes de origem das primeiras universidades. A primeira, denominada 'espontânea', refere-se àquelas que foram resultados da expansão 
de escolas já existentes. São exemplos as universidades de Paris, Bolonha e Oxford. Há, também, aquelas que surgiram por 'migração', ou secessão, em virtude de conflitos entre as autoridades locais e os homens que se dedicavam ao saber. Muitas vezes, essas universidades funcionavam antes mesmo de serem oficializadas, são exemplos as universidades de Cambridge (nasceu da secessão de Oxford em 1208, porém só foi reconhecida em 13181, Orléans e Angers (nascidas da secessão da universidade de Paris, por volta de 1229-1231, reconhecidas em 1306 e 1337, respectivamente). A terceira forma, Verger denomina universidades 'criadas', pois foram instituídas pelo poder papal ou pelo poder imperial. Tiveram poucos resultados no século XIII, quando comparadas às universidades espontâneas, porém são notáveis pelo reconhecimento que a corporação começou a despertar. "Significava reconhecer na formação universitária, além de seu valor cultural e de seu prestígio, uma utilidade prática e um alcance político" (OLIVEIRA, 2006, p. 75).

Dessa maneira, a universidade surge como espaço completamente inovador, para atender, inicialmente, às demandas daqueles que procuravam diálogo para compreender tanto os novos conhecimentos que vinham se disseminando desde o século XII com a entrada de obras aristotélicas no Ocidente, quanto o desenvolvimento citadino que provocava novas interações entre os homens.

Assim, lembremos o fato de que a universidade foi o primeiro espaço de saber universalizante que o Ocidente construiu nos últimos dois mil anos. Universalizante no que diz respeito ao conhecimento e no que respeita a integração das pessoas. Também esse espaço delineou nossas identidades sociais e científicas. Por meio da sua memória poderemos, quiçá, nos aconselharmos sobre o seu futuro. Afinal, ela pode orientar nosso caminhar e agir. Concluímos reiterando algo que colocamos no início: se uma instituição existe há 800 anos e continua atuante (evidente dentro de novas condições e características), é porque ela ainda faz parte da História e continua construindo a identidade dos homens (OLIVEIRA, 2007, p. 1291.

Conforme a autora, a necessidade dessa instituição está ligada ao fato de que, por meio da ideia de 'saber universalizante', a universidade moldou a sociedade e as pessoas, orientando uma forma de agir e pensar que, antes de sua existência, não parecia possível. Essa abordagem nos leva a 
compreender a relevância de pensar as instituições por meio de suas características históricas. Entender a origem da universidade nos situa diante do quadro geral (totalidade) de existência da instituição, o que orienta diretamente nossa ação cotidiana. Isso é pertinente para que tenhamos a noção de que pertencemos à instituição, mas ela nos ultrapassa. Sua representação coletiva é maior do que a existência individual de cada um de nós que dela somos parte; é a essa ideia que precisamos nos ater, para não sucumbir à vaidade, ao egocentrismo e à ilusão de poder. Todos esses sentimentos fazem parte dos homens, porém, quando priorizamos o desenvolvimento pleno do conhecimento, tendemos a torná-los secundários em nossas ações para que nossa mente se mantenha aberta à necessidade essencialmente humana de buscar o saber.

Vemos, assim, que, por meio do entendimento da origem da universidade podemos considerar, entre muitos aspectos, a motivação original para sua criação e a relevância social que esse espaço conquistou. Em síntese, a corporação universitária surge como forma de os homens se reunirem para, dentro da realidade vivenciada, compreender disseminar e desenvolver o conhecimento a que tinham acesso. Com isso, ao pensarmos na universidade 228 contemporânea, precisamos compreender que, evidentemente, não se trata mais da mesma forma de sociedade, as demandas, também, não são mais as mesmas, portanto, a universidade revestiu-se de novas responsabilidades e encargos. Porém, diante dessa nova realidade, a questão que permanece agora sob a luz dos motivos que originaram a instituição - é: qual a finalidade do ensino superior? Será que a universidade atende aos anseios de quem a ela recorre para obter conhecimentos necessários para o exercício de uma profissão? Será que há ainda quem busque na universidade o diálogo entre os saberes disponíveis atualmente? $\mathrm{E}$, ainda, é possível indagar se, em nosso país, a universidade exerce seu caráter 'universalizante', em que a teoria e a prática são mutuamente essenciais para a formação dos alunos.

Além de cientificamente qualificado, o professor deve poder reconhecer a relevância de seu próprio trabalho para a reflexão permanente sobre o todo; ele deve ser capaz de introduzir no diálogo filosófico esse conhecimento, sem generalização diletante ou apressada. Isto pressupõe, sem dúvida, alguma coisa a mais, isto é, que em caso de necessidade ele não se recuse a trazer para o debate as últimas posições. [...] Contudo a mais resoluta simplicidade exige que o professor, como tal, se manifeste 
necessariamente, quando solicitado acerca do problema da coesão global do mundo (PIEPER, 2000, p. 8, grifo nosso).

Conforme o autor, a principal característica do professor universitário é a capacidade do diálogo, do debate e do posicionamento com base filosófica. Isso porque em seu entendimento a universidade é uma instituição caracterizada, principalmente, por alguns aspectos, como: a cristalização das "[...] experiências humanas grandes e fundamentais"; pelos vocábulos universum e universitas, que conferem o vínculo com a totalidade do real (PIEPER, 2000, p. 2, 3, 19); e, consequentemente, pela ideia da disputatio escolástica, que "[...] não recusava nenhum argumento e nenhum contendor, prática que obrigava, assim, à consideração temática sob um ângulo universal". Abarcar o todo, dialogar e debater sobre as ciências específicas, inserindo-as no universo geral dos conhecimentos humanos, transcendendo-as, seria o objetivo fundamental e original da instituição. Para o autor, o que faz com que a universidade seja uma instituição necessária, não é somente a ciência, mas também, esse caráter de ser o local onde o conhecimento é debatido e inserido no todo da realidade. Esse é o espírito da universidade: replicar, coletivamente, o espírito humano, pois a mente humana é essencialmente filosófica, vislumbra a realidade por completo, questionando-a e, por isso mesmo, exerce sua capacidade de transformação. Assim, Pieper traça um quadro amplo do significado da universidade na sociedade. Indica sua 'utilidade' que, além de formar profissionais técnicos, pode ser definida como desenvolver o pensamento de seres que são, por essência, pensantes. Com base nos ensinamentos de Tomás de Aquino, Pieper entende que, apesar de termos a capacidade de utilizar a razão, é preciso que ela seja desenvolvida para ser colocada em prática.

Com base nessa linha de raciocínio, podemos afirmar que a ação educativa só pode ser praticada efetiva e qualitativamente por meio do conhecimento que o educador possui. $\bigcirc$ professor que dispensa o conhecimento histórico - e que, muitas vezes, dispensa junto a reflexão filosófica - prescinde da essência (teórica e prática) de seu ofício que consiste, basicamente, em valorizar o pensamento reflexivo. E, conforme Tomás de Aquino na questão De magistro, é possível para o homem ensinar somente aquilo que ele conhece em ato (TOMÁS DE AQUINO, 2001). Como ensinar os alunos a valorizar o conhecimento, se o professor não o valoriza? E se ambos não o valorizam, qual o sentido das instituições educativas para a sociedade? 
Desse modo, não é só uma questão pragmática que nos leva a buscar conhecer a história, ou outras ciências. A utilidade daquilo que aprendemos pode nem sempre ser imediata e aplicável a situações cotidianas, mas é útil no sentido de desenvolver o intelecto, a capacidade de compreender, em longo prazo, o que acontece a nossa volta e, principalmente, de entender - ou, ao menos, tentar - a natureza ou condição humana. E, nesse sentido, se trabalhamos no âmbito da educação, assimilar essas questões é de vital importância.

A prática educativa é essencialmente uma modalidade técnica e política de expressão do universo simbólico e um investimento formativo nessas práticas [...].

O conhecimento é o instrumento fundamental para oferecer referências na condução da existência humana [...].

Uma vez que a intencionalização de nossa prática histórica depende de um processo de significação simultaneamente epistêmico e axiológico, são imprescindíveis as referências éticas do agir e a explicitação do relacionamento entre ética e educação (SEVERINO, 2012, p. 91).

Severino observa a relação entre a teoria e a prática, indicando que a educação fornece as referências conceituais e axiológicas para um agir ético, portanto, político. É o conhecimento que aprimora a ação ética dos indivíduos e, consequentemente, as relações sociais. Nesse sentido, no fortalecimento do intelecto, da subjetividade, é que é possível ao homem aprimorar a prática produtiva, política e cultural. Evidentemente, não é somente a escola ou a universidade que participam dessa construção de referências conceituais e valorativas, porém são essas instituições as responsáveis em nossa sociedade por oferecer formalmente, de maneira intencional e sistematizada, esses saberes.

Salientamos que, ao mesmo tempo que deixamos o conhecimento em segundo plano nas atividades e formação docentes, manifestamos certa indignação com o fato de que há outras instâncias sociais que exerceriam forte pressão para que a educação não se concretizasse adequadamente. É como se existisse uma 'pressão', externa às instituições educativas, que impedisse ou dificultasse a realização do trabalho. A esse propósito, Morin afirma:

Antes de tudo, existe uma pressão superadaptativa, que leva a adequar o ensino e a pesquisa às demandas econômicas, técnicas 
e administrativas do momento; a conformar-se aos últimos métodos, às últimas estimativas do mercado, a reduzir o ensino geral, a marginalizar a cultura humanista. Ora, na vida como na história, a superadaptação a condições dadas nunca foi um indício de vitalidade, mas prenuncio de senilidade e morte pela perda da substância inventiva e criadora (MORIN, 2015, p. 83).

Portanto, cabe ao professor essa tarefa de não deixar que o ensino reduza-se a uma pequena, quase insignificante e passageira parcela da vida humana que é o presente e o cotidiano. Faz parte do ofício, enfrentar as forças e os discursos que contrariam uma formação aprofundada e que questionam o valor do conhecimento e da disciplina/responsabilidade, isolando-o em teoria ou prática, na educação formal. Em todas as outras profissões, essa seria uma atitude salutar, mas, no caso da docência, é a condição que sustenta o professor e as instituições educacionais como entes necessários à sociedade. Se o conhecimento não perpassar os principais processos e procedimentos das escolas e universidades, constituindo-se em princípios e finalidades, como dizer que a educação formal está se concretizando? Como dizer que há excesso de teoria em um ensino que mal prioriza a leitura?

Como vimos inicialmente, há um hábito impregnado, atualmente, na sociedade e que atinge, sobremaneira, as instituições educacionais, que consiste em 'mascarar' os problemas. Entre os motivos que levaram à formação dessa atitude, podemos apontar o desconhecimento, voluntário ou não, da essência dessas instituições. Começamos por desqualificar as avaliações de aprendizagem (especialmente se o desempenho for ruim) e, concomitantemente, a afastar a responsabilidade pelo baixo desempenho, atribuindo a outras instâncias da sociedade a 'culpa' pelas ações praticadas e pelos resultados obtidos.

Na educação, essa responsabilidade pelo mundo assume a forma de autoridade. A autoridade do educador e as qualificações do professor não são a mesma coisa. Embora certa qualificação seja indispensável para a autoridade, a qualificação, por maior que seja, nunca engendra por si só autoridade. A qualificação do professor consiste em conhecer o mundo e ser capaz de instruir os outros acerca deste, porém sua autoridade se assenta na responsabilidade que ele assume por este mundo (ARENDT, 2011 , p. 239). 
Assim, a função do professor assume outro contorno. Sua necessária qualificação, ou seja, o conhecimento que precisa dominar, não está desvinculado de sua autoridade, porém esta se assenta em um comportamento de comprometimento não só com sua própria instrução, mas também com a de seus alunos. No texto do qual esse excerto foi retirado, Arendt trata da crise na educação e se refere, essencialmente, à formação do ser humano na infância. A autora destaca que, ao educar, o adulto precisa reconhecer-se como responsável pelo mundo, pela realidade tal qual ela se apresenta no presente. Destituir-se dessa responsabilidade é abandonar a autoridade e, por conseguinte, negligenciar a disciplina a ser exercida perante os mais jovens. Se em outras áreas essa atitude é importante, na educação é fundamental porque ensinamos, acima de tudo, pelo exemplo.

Desse modo, especialmente no caso do ensino superior, é fundamental que os envolvidos não se isentem da responsabilidade por sua função institucional e social. Nesse sentido, discursos, comportamentos e, essencialmente, o conhecimento presente neles, são considerados objetos de ensino. Os professores universitários, principalmente aqueles que formam outros docentes, são os responsáveis por manter a característica essencial da instituição de

232 conservar e valorizar os saberes acumulados pela humanidade. Com efeito, a possibilidade de conservação só se efetiva com a demonstração de que o conhecimento é valorizado, é um comportamento que precisa ser assimilado para que seja, também, ensinado. Essa compreensão só é possível quando consideramos a atuação do indivíduo e os resultados sociais dessa atuação. Assim, a conduta dos professores; a forma como exercem e ensinam a disciplina; até que ponto assumem responsabilidades; qual o grau de coerência e prudência desses profissionais: são questões relevantes para ser pensadas nesse debate e, fundamentalmente, na formação da pessoa, especialmente dos alunos/acadêmicos.

\section{Considerações finais}

$\bigcirc$ papel social da universidade na conservação dos conhecimentos produzidos pela humanidade cumpre-se pela ação dos homens que dela fazem parte. Por esse motivo, iniciamos este texto com um discurso de um professor na pós-graduação que, aliado aos estudos que realizamos, propiciou uma reflexão sobre a disciplina em seu sentido de responsabilidade e esforço. 
Como pesquisamos a história da educação na perspectiva de longa duração, pensamos a educação inserida no todo da história humana, como prática coletiva sobre a qual cada um de nós, professores, tem responsabilidade.

Nesse sentido, a universidade medieval surge como objeto de pesquisa que nos possibilita compreender a essência original desse espaço dedicado ao saber. Essa característica deve permanecer, pois essa conservação é que asseguraria à instituição o seu papel fulcral na formação da pessoa, mas, para isso ocorrer, é preciso que a ação do professor, norteada pelo empenho e responsabilidade, seja direcionada ao conhecimento. É, pois, desse modo que consideramos que o comprometimento, a responsabilidade e o empenho com que professores exercem seu ofício deveria, também, constituir-se em objeto de pesquisa e de ensino, especialmente quando se trata da formação docente. Para nós, historiadoras da educação, são essas qualidades que podem conduzir a apreensão dos conhecimentos de modo que, efetivamente, façam parte de nossas ações.

Há outras maneiras de encarar a mensagem? Certamente. Porém, consideramos, nessa análise, o quadro crítico da educação no país, o baixíssimo nível de aprendizagem dos alunos nas escolas e todas as limitações com que esses mesmos alunos têm chegado aos cursos superiores ${ }^{13}$. São limitações impostas, sobretudo, pelas dificuldades /representadas no decorrer do texto pelos Inaf) em leitura e escrita, que restringem a aprendizagem de todas as outras disciplinas, por conseguinte, prejudicam a formulação de ideias e a organização do pensamento. Logo, devemos refletir se é o caso de simplificar a formação do professor, ou, pelo contrário, reforçar que é uma profissão árdua e que, para exercê-la, é necessária muita disciplina e que, justamente por isso, é um trabalho muito gratificante.

Apresentamos algumas informações que indicam uma preocupação evidente dos profissionais da área da educação em buscar 'culpados' para os problemas educacionais. Uma lista de motivos para que o professor não realize seu trabalho é insistentemente exposta: o desinteresse dos pais pela educação formal dos filhos, o salário baixo que leva à sobrecarga de trabalho em dupla jornada para complementar a renda. Outro motivo muito frequente é o 'sistema', seja ele político ou econômico. É como se houvesse uma pressão externa para que fosse oferecida uma educação formal aligeirada e voltada somente para o mercado de trabalho. Mas, o que causa até mesmo constrangimento é que mais de $90 \%$ dos professores no país consideram que os responsáveis por não 
aprenderem são os próprios alunos, que não se esforçam o suficiente, e suas famílias que não colaboram com os deveres de casa ${ }^{14}$. Como apontamos no decorrer do texto, é o paradoxo de exigir cada vez menos atenção e disciplina por parte do aluno e, por outro lado, esperar que ele desenvolva e, no caso das licenciaturas, ensine essas mesmas características.

De fato, esses aspectos fazem parte da realidade, do cotidiano do professor, porém eles devem ser assim considerados: como parte do trabalho. Não são justificativas para que o trabalho não se desenvolva, são os desafios que precisam ser enfrentados. Mesmo porque estes não são fatos desconhecidos, as pessoas quando adentram nos cursos de licenciatura conhecem essa realidade, sabem sobre boa parte dessas dificuldades. Contudo, além de não receberem os conhecimentos necessários para lidar com essa realidade le a partir dela), têm, muitas vezes, o hábito de buscar culpados reforçado pelos professores das universidades que, por sua vez, também parecem isentar-se do enfrentamento dessas questões. Difícil imaginar uma profissão que não tenha desafios, a docência, por ser tão complexa, evidentemente, possui desafios também complexos. Por esse motivo, procuramos ressaltar a necessidade de que o professor busque compreender a base de sua função social, para 234 que não transfira suas responsabilidades e, com isso, como afirmou Hannah Arendt, prive-se da autoridade para resolver os problemas que the competem. Odomínio e a valorização do trabalho demandam que os profissionais se responsabilizem e busquem soluções para os problemas concernentes à profissão que exercem. As especificidades da docência acentuam essa necessidade, pois a personalidade do professor, a forma como lida com suas responsabilidades, suas virtudes e vícios, como apontamos anteriormente com Severino e Arendt, constituem o conjunto de conhecimentos a ser ensinado.

Para pensar sobre nosso papel, nossas ações na sociedade e sobre a função das instituições educativas, é necessário ir além dos aspectos imediatos. Quanto mais distante na história buscarmos a essência de conceitos e instituições, as chances de nos depararmos com um conhecimento mais aprofundado sobre nós mesmos aumentarão. Abarcar o todo não significa saber tudo o que há para se saber - o que seria improvável e improdutivo. É, sim, a atitude diante da realidade, é a noção de que há sempre muito que aprender (o que requer humildade e esforço) e de que todos esses conhecimentos estão, necessariamente, vinculados à teia da realidade (o que requer amplitude de pensamento). 
Essas reflexões vêm sendo realizadas em nosso grupo de pesquisa (NOME GRUPO), fazemos um esforço constante por valorizar os clássicos, por meio da leitura, da pesquisa, das relações intertextuais, dos debates e da reflexão sobre a importância que esses homens do passado possuem em nossas vidas. Portanto, chegamos a essas considerações apoiados nos autores aqui apresentados, mas, também, em todos aqueles que temos estudado, como Aristóteles, Agostinho, Hugo de São Vitor, Boaventura de Bagnoregio, Guilherme de Ockham, entre outros pensadores de tempos históricos distintos que indicam a permanência do conhecimento como a essência das instituições educacionais. Todos eles nos ensinam que nossos pensamentos e ações são aprimorados por meio da disciplina para o estudo e que o mestre tem o papel fundamental de ensinar tanto o conteúdo quando a atitude para a aprendizagem. Tomás de Aquino sintetiza essa ideia em uma de suas questões disputadas sobre a verdade, ao afirmar que o mestre não infunde a luz da razão no aluno, mas, por meio de suas ações, ajuda essa luz a caminhar para a verdade, para a perfeição do conhecimento.

Assim, entendemos que a abertura de nossas instituições de ensino superior para o 'todo', tratado pelo filósofo Pieper, passa pela vontade e escotha dos professores, pela sua atuação. Consideramos importante ressaltar que não estamos em busca de atitudes 'salvacionistas' da educação, ou mesmo de simplismos, tratamos do que consideramos ser a base para a compreensão do nosso ofício e que, a nosso ver, apesar de ser um problema significativo, é pouco discutido. A função social do professor, nesse sentido, não é externa a ele próprio, é exercida em relação direta à forma como o professor lida internamente com o conhecimento.

\section{Notas}

1 Disciplina, no universo que estamos analisando, é o hábito que cada indivíduo tem em relação as suas ações cotidianas. Quando nos referimos à disciplina do professor estamos considerando o modo diário da sua docência, em termos de dedicação e responsabilidade. É preciso alertar ainda que o conceito de hábito que usamos é o de Aristóteles presente na obra Ética a Nicômaco.

2 Na perspectiva kantiana, a disciplina promove a liberdade humana, pois quanto mais o homem possui controle racional sobre suas ações, mais tem condições de exercer a liberdade coletivamente. É, portanto, necessário que desde cedo o jovem aprenda este hábito (KANT, 2011 ). 
3 No decorrer do texto, será possível notar que tratamos escola e universidade como instituições que possuem uma 'via de mão dupla', que as vincula em termos de resultados.

4 Sempre que utilizarmos o termo relativo à 'naturalização' de comportamentos, estaremos nos referindo à aquisição de hábitos e formação de disposições virtuosas ou não, conforme as definições de hábito encontradas em Aristóteles (Ética a Nicômaco, liv. II) e Tomás de Aquino (Suma teológica, I la $l$ ae, q. 49-54).

5 "Não dá para formar um professor só lendo Piaget", foi a frase do ministro da Educação Aloízio Mercadante, que mereceu aplausos em encontro com mil secretários municipais da área de ensino em 2013. Disponível em: http://www1.folha.uol.com.br/educacao/2013/08/1321237-formacao-do-professor-tem-muita-teoria-e-pouca-pratica.shtml. Consulta em: 5 abr. 2016.

6 No caso do curso de Pedagogia, por exemplo, a resolução CNE/CP n. 1, de 15/05/2006, que institui as Diretrizes Curriculares Nacionais para os cursos de graduação nessa área, trata pedagogia e docência como se fossem a mesma coisa e limita a formação e a atuação do pedagogo com um currículo aligeirado e conceitualmente equivocado (LIBÂNEO, 2006).

7 Importante, nesse sentido considerar a ideia de currículo apresentada por Tomaz Tadeu da Silva (1999), no qual ele tece uma analogia entre o currículo e a carteira de identidade.

8 "Disse que a sociedade vive da morte dos indivíduos. Não se poderá dizer igualmente que uma sociedade vive da morte das suas teorias? Visto que a melhor maneira de assassinar uma ideia é venerá-la. [...] A partir do momento em que tenho uma certeza, a certeza é o melhor dos meus tranquilizantes[...]" (MORIN; CYRULNIK, 2004, p. 43-44).

9 Em 2014, a USP passou para a $201^{a}$ posição e a UNICAMP permaneceu no mesmo patamar.

10 Professor emérito da Faculdade de Filosofia, Letras e Ciências Humanas da USP.

236 11 Uma busca no Google sobre as festas da USP indica que há um site (baladasnausp.com. br) organizado para a venda de ingressos e divulgação dos eventos. Em jornais e revistas é possível ver os resultados dessas festas, com denúncias de abuso sexual, uso de drogas ilícitas e, até mesmo, mortes.

12 Recomendamos a leitura do artigo de Oliveira (2009): A importância da leitura de escritos tomasianos na formação docente.

13 PISA revela esse quadro a cada 3 anos. Em 2012, o Brasil ficou em 58 , entre 65 avaliados. Em leitura, 49,2\% dos alunos não alcança o nível 2, pois não conseguem compreender as relações entre as informações presentes num texto. Disponível em: http://educacao.vol.com.br/ noticias / $2013 / 12 / 03$ / pisa-desempenho-do-brasil-piora-em-leitura-e-empaca-em-ciencias. htm. Consulta em: 10 maio 2016.

14 Para $91 \%$ dos professores o baixo desempenho de aprendizagem é culpa dos próprios alunos e 95\% atribui a culpa à família. Porém, ao tratar das questões que envolvem o trabalho docente, o percentual não excedem os 30\%. Disponível em: http://www.gazetadopovo.com.br/vida-e-cidadania/ para-professores-deficit-no-ensino-e-culpa-dos-alunos-euhry 1 kdvsjhk3zknzzkzeb7y. Consulta em: 5 abr. 2016.

\section{Referências}

ALENCASTRO, Catarina. Brasileiro lê, em média, quatro livros por ano, revela pesquisa.

Globo, Rio de Janeiro, 28 mar. 2012 . Disponível em: http: / /oglobo.globo.com/sociedade/ 
educacao/brasileiro-le-em-media-quatro-livros-por-ano-revela-pesquisa-4436899. Acesso em: 5 abr. 2016.

AlLEGRETTI, Fernanda. Artigos de segunda. Veja, São Paulo, n. 50, p. 104-1 10, 10 dez. 2014.

ARENDT, Hannah. Entre o passado e o futuro. São Paulo: Perspectiva, 2011.

ARISTÓTELES. Ética a Nicômaco. 3. ed. Bauru: Edipro, 2009.

BASE Nacional Comum Curricular. Brasília: MEC/CONSED, 2015. Disponível em: http:// basenacionalcomum.mec.gov.br. Acesso em: 10 maio 2016.

BLOCH, Marc. Apologia da história, ou, o ofício do historiador. Rio de Janeiro: Zahar, 2001.

G1 GLOBO. 2014. Brasil fica de novo fora do top 200 de ranking das melhores universidades. Disponível em: http://gl globo.com/educacao/noticia/2014/10/brasil-fica-de-novo-fora-do-top-200-de-ranking-das-melhores-universidades.html. Acesso em: $1^{\circ}$ dez. 2014.

LIBÂNEO, José Carlos. Diretrizes Curriculares da Pedagogia: imprecisões teóricas e concepção estreita da formação profissional de educadores. Educação \& Sociedade, Campinas, v. 27 , n. 96, p. 843-876, out. 2006.

KANT, Immanuel. Sobre a pedagogia. Piracicaba: Editora da Universidade Metodista de Piracicaba, 2011.

MARTINS, José de Souza. A USP sob ataque. O Estado de S. Paulo, 29 nov. 2014. Disponível em: http://alias.estadao.com.br/noticias/geral,a-usp-sob-ataque, 1599621. Acesso em: $1^{\circ} \mathrm{dez} .2014$.

MORIN, Edgar. Os sete saberes necessários à educação do futuro. 2. ed. São Paulo: Cortez; Brasília: UNESCO, 2000.

MORIN, Edgar; CYRULNIK, Boris. Diálogo sobre a natureza humana. Lisboa: Instituto Piaget, 2004.

MORIN, Edgar. A cabeça bemfeita: repensar a reforma, reformar o pensamento. 22. ed. Rio de Janeiro: Bertrand Brasil, 2015.

MOURA, Rafael Moraes. Universitários brasileiros leem apenas de 1 a 4 livros por ano, revela Andifes. O Estado de S. Paulo, São Paulo, 13 ago. 2011 . Disponível em: http:// 
Reflexões sobre a função social do professor na universidade

www.estadao.com. br/noticias/geral, universitarios-brasileiros-leem-apenas-de-1-a-4-livros-por-ano-revela-andifes-imp-,758017. Acesso em: 10 maio. 2016.

OLIVEIRA, Terezinha. A universidade medieval: uma memória. Mirabilia, n. 6, p. 63-78, jun./dez. 2006.

OLIVEIRA, Terezinha. Origem e memória das universidades medievais: a preservação de uma instituição educacional. Varia história, Belo Horizonte, v. 23, n. 37, p. 1 13-129, jan./ jun. 2007.

OLIVEIRA, Terezinha. A importância da leitura de escritos tomasianos para a formação docente. Notandum, São Paulo/Porto, n. 21 , p. 75-83, set.-dez. 2009.

PIEPER, Josef. Abertura para o todo: a chance da universidade. Mirandum, n. 9, jan./jun. 2000. Disponível em: http://www.hottopos.com.br/mirand9/mirand9.htm. Acesso em: 1 dez. 2015.

POLATO, Amanda. Zoara Failla: "Se o professor não é leitor, não consegue transmitir o prazer da leitura". Época, 11 set. 2012. Disponível em: http://revistaepoca.globo.com/ Sociedade/noticia/2012/09/zoara-failla-se-o-professor-nao-e-leitor-nao-consegue-transmitir-o-prazer-pela-leitura.html. Acesso em: 5 abr. 2016.

238 SEVERINO, Antônio Joaquim. Educação, sujeito e história. São Paulo: Olho d'água, 2012.

SILVA, Tomaz Tadeu da. Documentos de identidade: uma introdução às teorias do currículo. Belo Horizonte: Autêntica, 1999.

SIMAS, Anna. Um terço dos professores não lê livros. Gazeta do Povo, Curitiba, 9 fev. 2013. Disponível em: http://www.gazetadopovo.com.br/vida-e-cidadania/um-terco-dos-professores-nao-le-livros-cyfb5mgbwkgu8czf3cehrrnj0. Acesso em: 5 abr. 2016.

TAKAHASHI, Fábio. Muita teoria e pouca prática formam os professores. Folha de S. Paulo, São Paulo, 4 ago. 2013. Disponível em: http://wwwl.folha.uol.com.br/ educacao/2013/08/1321 237-formacao-do-professor-tem-muita-teoria-e-pouca-pratica. shtml. Acesso em: 5 abr. 2016.

TELES, Lília. 70\% dos brasileiros não leram em 2014, diz pesquisa da Fecomércio-RJ. G1 Globo, $1^{\circ}$ abr. 2015. Disponível em: http://gl.globo.com/jornal-da-globo/ noticia/20 1 5/04/70-dos-brasileiros-nao-leram-em-20 14-diz-pesquisa-da-fecomercio-ri. html. Acesso em: 5 abr. 2016.

TOMÁS DE AQUINO. De magistro. São Paulo: Martins Fontes, 2001. 
TOMÁS DE AQUINO. Suma teológica. São Paulo: Loyola, 2005. (v. IV. I seção, II parte)

Doutoranda Lais Boveto

Universidade Estadual de Maringá

Programa de Pós-Graduação em Educação

Grupo Transformações Sociais e Educação na Antiguidade e Medievalidade

E-mail | laisboveto@hotmail.com

Profa. Dra. Terezinha Oliveira

Universidade Estadual de Maringá Departamento de Fundamentos da Educação Programa de Pós-Graduação em Educação Bolsista produtividade CNPq-1D

Líder do Grupo Transformações Sociais e Educação na Antiguidade e Medievalidade | GTSEAM E-mail | teleoliv@gmail.com

Recebido 31 maio 2016 Aceito 20 dez. 2016 